\title{
Self-organized Nano-cone Arrays in InP/InGaAs/InGaAsP Microstructures by Irradiation with ArF and KrF Excimer Lasers
}

\author{
Neng Liu, Khalid Moumanis, Jan J. Dubowski* \\ Laboratory for Quantum Semiconductors and Photon-based BioNanotechnology \\ Department of Electrical and Computer Engineering \\ Université de Sherbrooke, Québec, Canada J1K 2R1 \\ *URL: http://www.dubowski.ca
}

\begin{abstract}
We discuss the effect of $\operatorname{ArF}\left(\lambda_{\text {laser }}=193 \mathrm{~nm}\right)$ and $\operatorname{KrF}\left(\lambda_{\text {laser }}=248 \mathrm{~nm}\right)$ excimer laser irradiation of InP/InGaAs/InGaAsP quantum well (QW) microstructures on surface morphology of the top InP layer. The irradiation was carried out in air with lasers delivering up to 700 pulses of fluence from 82 to $142 \mathrm{~mJ} / \mathrm{cm}^{2}$. We observe the formation of nano-cone structures having their period increasing from 450 to $1080 \mathrm{~nm}$ for $\mathrm{KrF}$ laser, and from 675 to $875 \mathrm{~nm}$ for ArF laser, in proportion to the laser fluence and pulse number. The chemical and structural modification of the laser irradiated surface has resulted in the enhancement of the QW photoluminescence emission up to 1.4 times when compared to the non-processed material. Thus, the excimer laser processing of the surface of InP capped InGaAs/InGaAsP QW microstructures using relatively low pulse fluence, has been found attractive for the fabrication of enhanced optical emission semiconductor devices.

DOI:10.2961/jlmn.2012.02.0001
\end{abstract}

Keywords: InP/InGaAs/InGaAsP quantum well microstructures, excimer laser irradiation, surface morphology, nano-structure formation, atomic force microscopy, photoluminescence

\section{Introduction}

Laser processing of semiconductor materials has attracted continuous interest due to its potential in delivering microfabrication solutions of interest for advanced photonic and electronic devices. Due to the relatively low thermal and chemical stability of III-V compound semiconductors, laser irradiation at a relatively moderate pulse fluence can alter the surface morphological, chemical and physical properties of these materials [1]. For instance, the formation of nano-cone arrays was observed on the surface of InGaAs cap of the InGaAs/InGaAsP/InP quantum well (QW) microstructure irradiated with an excimer laser [2]. Following the annealing in a rapid thermal annealing (RTA) furnace, the laser irradiated sites exhibited an enhanced photoluminescence (PL) emission from InGaAs QWs. The sub-micrometer surface features have also been observed on the surface of bulk InP [3] and diamond-like films [4] irradiated with femtosecond (fs) lasers, which illustrates that the formation of surface nanostructures does not require a strong thermal component typical of nanosecond lasers [5]. It has also been reported that the irradiation of bulk InP with a low fluence $\left(\mathrm{F} \approx 80 \mathrm{~mJ} / \mathrm{cm}^{2}\right)$ of a nanosecond UV laser $(\lambda=337$ $\mathrm{nm})$ leads to the formation of mounds and increased surface roughness of this material in proportion to the number of irradiating laser pulses [6].

Excimer lasers offer wafer level processing and these tools have been successfully applied by the microelectronics industry for sub-micrometer resolution photolithography. We have been investigating the application of 308 [2], 248 [7] and $193 \mathrm{~nm} \mathrm{[8]} \mathrm{excimers}$ for surface modification and bandgap engineering of III-V quantum semiconductors. This approach is attractive for processing of large size wafers, often in a single step, and without the need of using photolithography masks. Depending on the laser used, the investigated microstructure and the irradiation environment both enhanced quantum well intermixing (QWI), leading to blue shifting (shorter wavelength emission of the QW microstructure) [8], and, as well, suppressed QWI processes have been reported in [9]. The surface morphology of intermixed QW microstructures affects their photoluminescence (PL) and other optical properties [10]. For instance, it is known that inductively coupled argon plasma processing yields QWI material with decreased PL intensity [11]. Typically, excimer laser-induced surface modification of InP-capped QW microstructures results in the preferential loss of $\mathrm{P}$ atoms [8] and generation of different surface defects that promote the QWI process during the RTA step. Thus, it is of paramount importance to investigate both the morphology and chemical composition of altered III-V semiconductor surfaces as a function of laser parameters, such as pulse fluence and pulse number.

We have reported that the maximum band gap blue shift of the InP/InGaAs/InGaAsP microstructure irradiated in air with $\mathrm{KrF}$ [12] and $\mathrm{ArF}$ [8] lasers takes place for a relatively small number of pulses $(\mathrm{N}<100)$ and low pulse fluence $\left(\mathrm{F}<124 \mathrm{~mJ} / \mathrm{cm}^{2}\right)$. In this paper, we investigate surface morphology of such microstructures irradiated in air with up to 700 pulses of $\mathrm{KrF}$ and $\mathrm{ArF}$ excimer lasers delivering pulse fluence in the range of 95 to $142 \mathrm{~mJ} / \mathrm{cm}^{2}$.

\section{Experimental details}

A schematic cross-section of the InP/InGaAs/InGaAsP QW microstructure used in this experiment is shown in 
Fig.1. The microstructure was deposited on an S-doped InP substrate covered with a $1400 \mathrm{~nm}$ thick InP buffer. The active region, consisting of five 5.5-nm-thick InGaAs QWs separated by four $12 \mathrm{~nm}$ thick InGaAsP barriers, was designed to emit at $1.55 \mu \mathrm{m}$ at room temperature. The active region was confined by two 142-nm-thick graded bandgap InGaAsP microstructures. The top cladding InP layer was separated by a 10 -nm-thick InGaAsP etch stop layer. A $100 \mathrm{~nm}$ thick InGaAs contact layer on top of the microstructure was separated from the InP cladding layer by a second 50 -nm-thick InGaAsP etch stop layer. The whole microstructure was covered with a 400-nm-thick undoped InP sacrificial layer.

\begin{tabular}{|ll|}
\hline InP & $400 \mathrm{~nm}$ \\
\hline InGaAs & $100 \mathrm{~nm}$ \\
\hline InGaAsP & $50 \mathrm{~nm}$ \\
\hline InP & $1200 \mathrm{~nm}$ \\
\hline InGaAsP & $10 \mathrm{~nm}$ \\
\hline InP & $200 \mathrm{~nm}$ \\
\hline $\begin{array}{l}\text { InGaAsP } \\
\text { (graded) }\end{array}$ & $142 \mathrm{~nm}$ \\
\hline $\begin{array}{l}\text { InGaAsP } \\
\text { InGaAs }\end{array}$ & $\begin{array}{l}12 \mathrm{~nm} \\
\text { InGaAsP } \\
\text { (araded) }\end{array}$ \\
\hline InP & $142 \mathrm{~nm}$ \\
\hline \multicolumn{2}{|c|}{ S doped InP } \\
\end{tabular}

Fig. 1 Schematic cross-section of the investigated $\mathrm{InP} / \mathrm{InGaAs} / \mathrm{InGaAsP}$ microstructures.

A series of $5 \mathrm{~mm}$ x $5 \mathrm{~mm}$ samples was obtained by, first, cleaving the QW wafer and, second, cleaning them with standard solvents. The samples were then irradiated with $\mathrm{ArF}$ and $\mathrm{KrF}$ lasers delivering 16 ns pulses of fluence in the range of $82-95 \mathrm{~mJ} / \mathrm{cm}^{2}$ and $109-142 \mathrm{~mJ} / \mathrm{cm}^{2}$, respectively. The absorption depth in InP is about 8 and 5 $\mathrm{nm}$ for $\operatorname{ArF}\left(\alpha=1.3 \times 10^{6} / \mathrm{cm}\right)$ and $\operatorname{KrF}\left(\alpha=1.8 \times 10^{6} / \mathrm{cm}\right)$ laser, respectively [13]. The ablation threshold of bulk InP is $\sim 100 \mathrm{~mJ} / \mathrm{cm}^{2}$ [14] and $\sim 140 \mathrm{~mJ} / \mathrm{cm}^{2}$ [15] for $\mathrm{ArF}$ and $\mathrm{KrF}$ laser, respectively. A double micro-lens fly-eye-array homogenized laser beam was used to project 0.9 and 1.4 $\mathrm{mm}$ diameter circular diaphragms on the sample surface using $\mathrm{ArF}$ and $\mathrm{KrF}$ lasers, respectively. A computer controlled X-Y-Z-Theta sample positioning allowed to process the investigated samples at numerous sites. The laser irradiation was carried out in an ambient air environment.

Room temperature PL measurements were carried out with a commercial mapper (Philips PLM-150). An $\mathrm{Nd}$ :YAG laser was used to excite the sample while the luminescence was dispersed by a monochromator and detected by an InGaAs photodiode array. The PL maps were obtained based on the QW (InGaAs) electron-hole recombination peak $(\lambda \approx 1550 \mathrm{~nm})$.

A Nikon microscope (Eclipse LV100) was used to collect optical images of the laser irradiated sites on the cap layer of the InP material. The sample surface morphology was also investigated with an atomic force microscope (AFM, Digital Instruments Nanoscope III) operating in a tapping mode. An etched single-crystal silicon tip with a rectangular, single beam cantilever (TESP from Digital
Instruments) was used for collecting AFM images. TESP tip radius is around $5-20 \mathrm{~nm}$, the cantilever spring constant is $20-100 \mathrm{~N} / \mathrm{m}$ and the resonance frequency is around 200$400 \mathrm{kHz}$. The tapping mode images were collected at a scan rate of $1.97 \mathrm{~Hz}$ for $5 \mu \mathrm{m} \times 5 \mu \mathrm{m}$ region, with 512 points per line. High accuracy measurements of surface roughness were carried out with a similar set of parameters as reported in the literature [16].

A commercial profiler (Tencore Alphastep 200) was used to measure the ablation depth of laser irradiated sites.

\section{Results and discussion}

\subsection{KrF laser irradiation of InP/InGaAs/InGaAsP microstructures}

An optical microscope image of a $\sim 1400 \mu \mathrm{m}$ diameter site obtained by the irradiation with 400 pulses of a $\mathrm{KrF}$ laser at $142 \mathrm{~mJ} / \mathrm{cm}^{2}$ is shown in Fig. 2. The presence of a darker region, of a diameter about $780 \mu \mathrm{m}$, can be seen in the center of the laser irradiated site. A closer inspection revealed that the whole surface of the laser irradiated site is covered with regularly organized nano-cone arrays, while in the central region (Fig. 2b) the nanostructure height is found greater and their periodicity shorter in comparison to the edge region (Fig. 2c).

(a)

) (b)

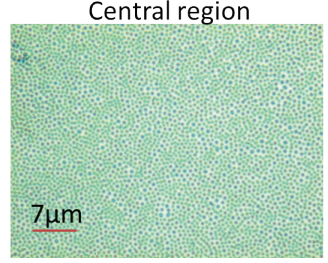

(c)

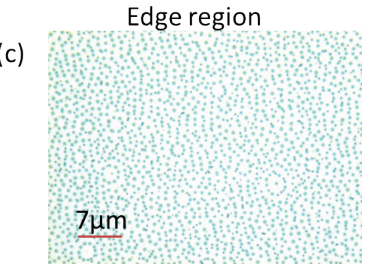

Fig. 2 Optical micrograph of the surface of an $\mathrm{InP} / \mathrm{InGaAs} / \mathrm{InGaAsP}$ microstructure irradiated with 400 pulses of a KrF laser at $142 \mathrm{~mJ} / \mathrm{cm}^{2}$ (a), along with high magnification images of the central (b) and edge (c) regions.

Fig. 3 shows an AFM micrograph of a site irradiated with the $\mathrm{KrF}$ laser at $142 \mathrm{~mJ} / \mathrm{cm}^{2}$ with 400 pulses. An array of nano-cones is clearly observed in this figure. As indicated by cross-section scans, the nano-cones are denser and taller in the central region (a) in comparison to the edge region (b). The average period of the nano-cones in the central region is $870 \mathrm{~nm}$, which compares to that of the edge region of $1320 \mathrm{~nm}$. The average height of the nanocone structures decreases from $188 \mathrm{~nm}$ in the central region to $141 \mathrm{~nm}$ in the edge region.

Fig. 4 compares optical microscopic images of sites irradiated with 100, 400 and 700 pulses of the $\mathrm{KrF}$ laser at fluence of $109 \mathrm{~mJ} / \mathrm{cm}^{2}$ (left panel) and $142 \mathrm{~mJ} / \mathrm{cm}^{2}$ (right panel). The central dark region is clearly observed in all 
cases, increasing in its intensity with both the pulse number and fluence.

More details concerning these microstructures can be observed in Fig. 5 that presents the AFM data. The site irradiated with 100 pulses of the $\mathrm{KrF}$ laser at $109 \mathrm{~mJ} / \mathrm{cm}^{2}$ (Fig. 5a) shows some evidence of surface roughening, but no obvious nano-cone structures. However, irradiation with the same number of pulses at $142 \mathrm{~mJ} / \mathrm{cm}^{2}$ leads to the formation of nano-cones, approximately $250 \mathrm{~nm}$ wide and up to $90 \mathrm{~nm}$ tall (Fig. 5b). The nano-cones increase in height and diameter with increasing pulse fluence and number, as evidenced in Figs. 5c-f.
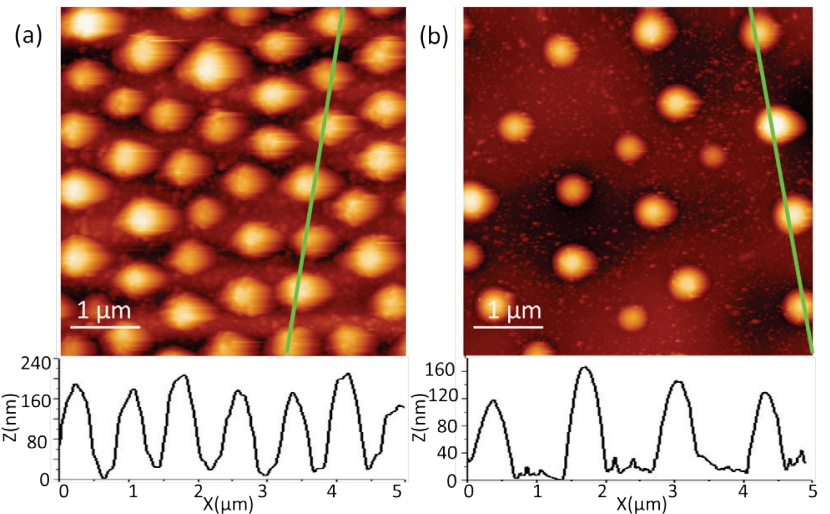

Fig. 3 AFM images of the central (a) and the edge (b) regions of a site irradiated with 400 pulses of the $\mathrm{KrF}$ laser at 142 $\mathrm{mJ} / \mathrm{cm}^{2}$.
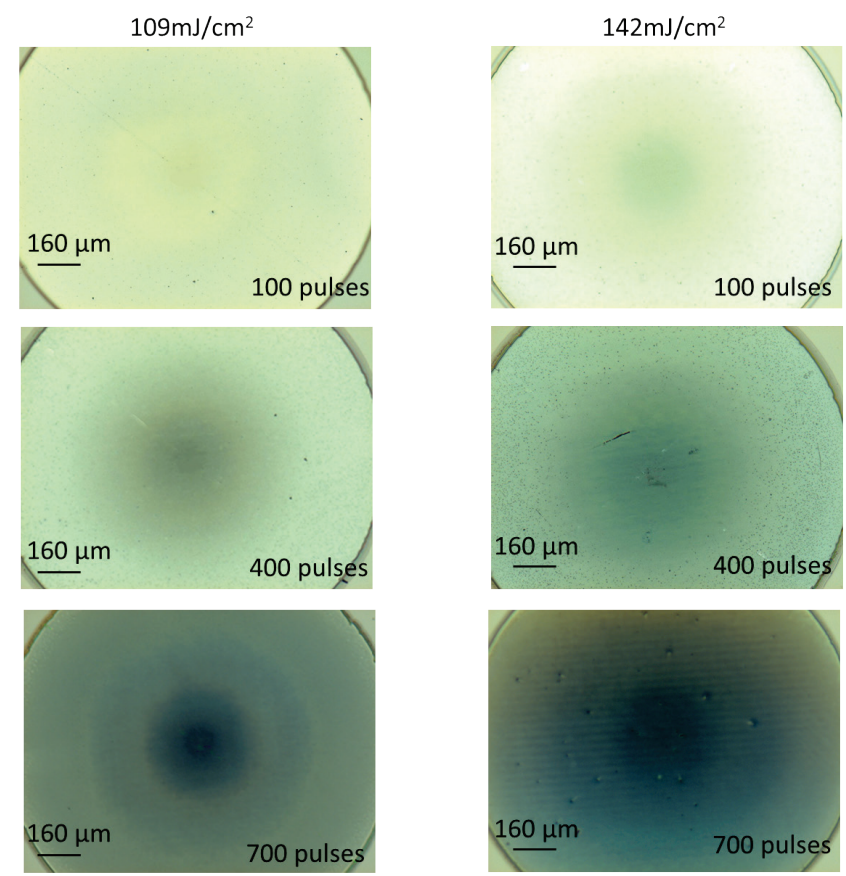

Fig. 4 Microscopic images of $\mathrm{KrF}$ laser irradiated sites at $109 \mathrm{~mJ} / \mathrm{cm}^{2}$ (left panel) and $142 \mathrm{~mJ} / \mathrm{cm}^{2}$ (right panel) with 100 , 400 and 700 pulses.

Fig. 6 shows the average height (a), size (b) and period (c) of the self-organized nano-cone structures observed in this experiment. The amplitude of these parameters increases with the pulse number and fluence, and saturates at 600 pulses. Nano-cones with a maximum average height of $274 \mathrm{~nm}$ have been observed, which demonstrates that some material of the InP cap layer has been ablated with the laser (from the initial $400 \mathrm{~nm}$ thickness).
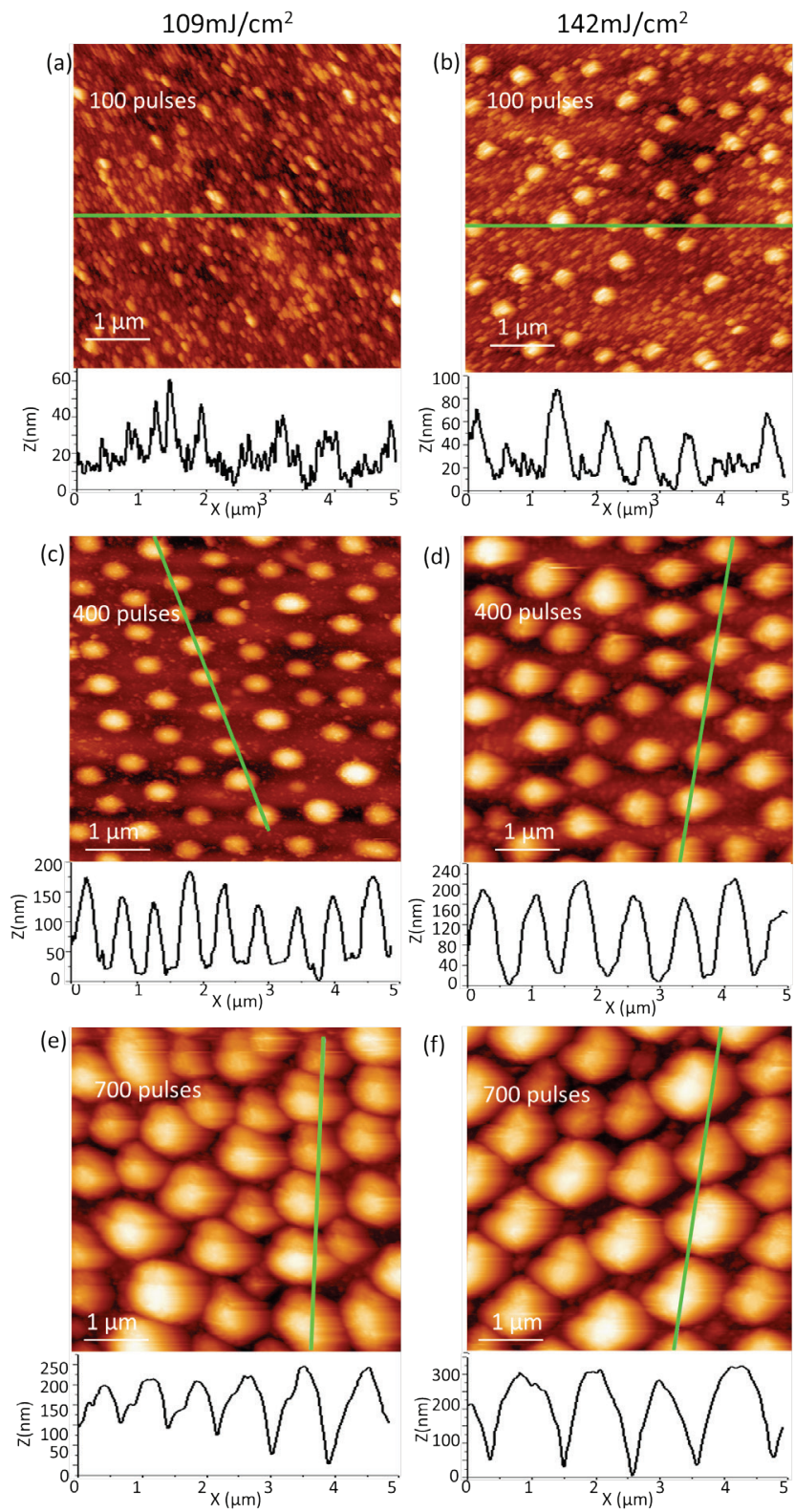

Fig. 5 AFM images and profiles along indicated lines in the central region the $\mathrm{KrF}$ laser irradiated sites at $109 \mathrm{~mJ} / \mathrm{cm}^{2}$ (left panel) and $142 \mathrm{~mJ} / \mathrm{cm}^{2}$ (right panel).

It has been reported that preferential removal of $\mathrm{P}$ takes place from InP at high temperatures due to the significantly higher vapor pressure of that element in comparison to In [15]. Our X-ray photoelectron spectroscopy (XPS) results of an excimer laser irradiated InP/InGaAs/InGaAsP microstructure in air showed that $\mathrm{In} / \mathrm{P}$ ratio increases with the pulse number [17], which is also associated with the formation of indium oxide as reported in literature [18]. The laser formed layer of indium oxide is under significant stress due to lattice mismatch with the InP layer. The stress accumulates on the sample surface as the number of laser pulses increases. The release of this mechanical stress, and related plastic deformation, are likely responsible for the formation of nano-cone structures through the modified Stranski- Krastanov growth [19]. Additionally, the surface 
temperature and the deformation strain are expected to increase with the laser fluence [20]. Thus, nano-

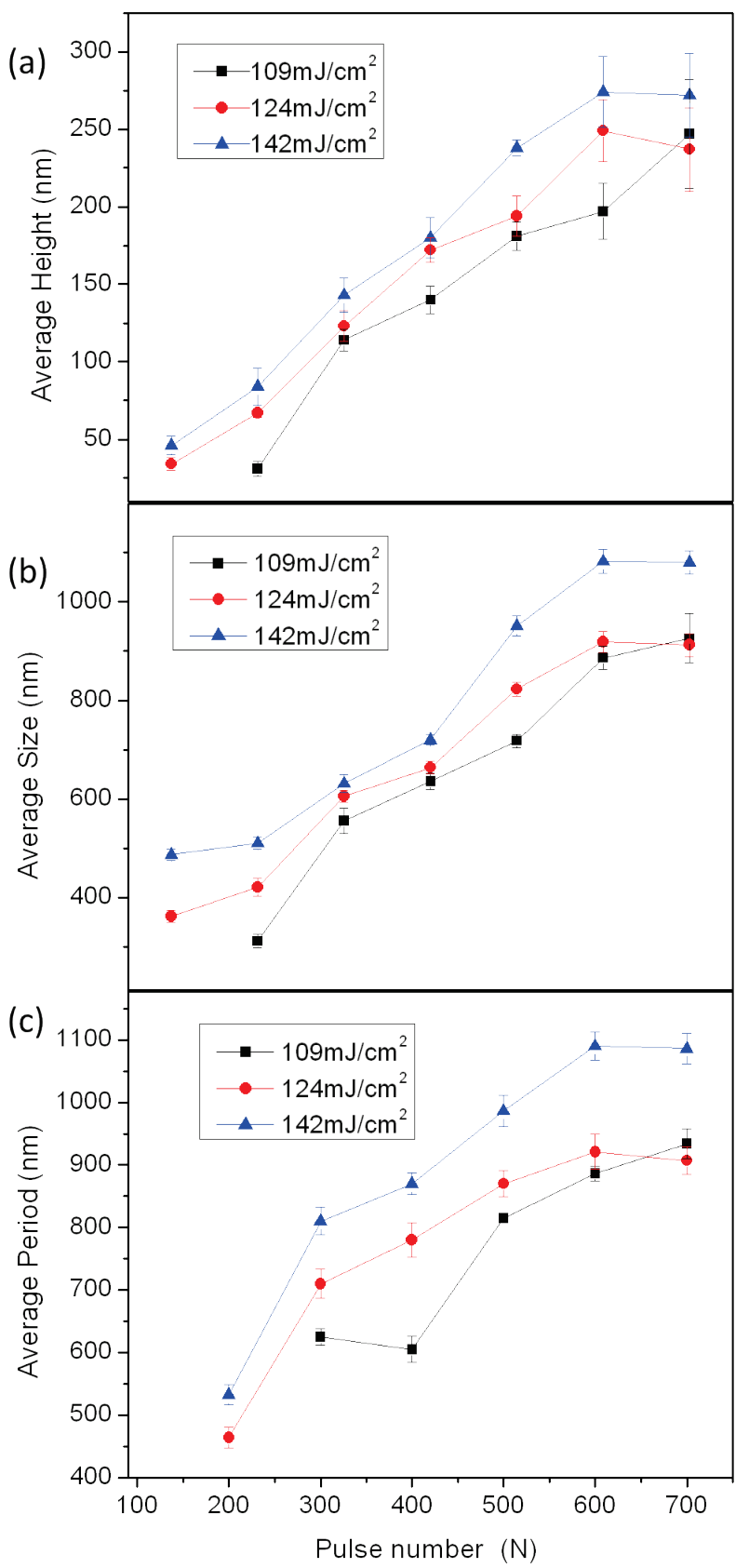

Fig. 6 Average height (a), size (b) and period (c) of self-organized nanostructures vs. pulse number of the $\mathrm{KrF}$ laser operating at 109 $\mathrm{mJ} / \mathrm{cm}^{2}, 124 \mathrm{~mJ} / \mathrm{cm}^{2}$ and $142 \mathrm{~mJ} / \mathrm{cm}^{2}$.

cone structure size, height and period increase with laser fluence and pulse number. The saturation behavior of these nano-cone structures growth at large pulse number $(\geq 600)$ indicates that the strain generated by the laser is relieved after a certain level of surface modification and material removal [6]. The quantitative description of the mechanism responsible for the formation of nano-cone structures and especially the formation of the zones of different density nano-cones observed within same laser irradiated sites requires a dedicating modeling. It is possible that formation of distinctly different zones of nano-cone structures is due to the intensity modulation of a coherent image of the mask projected through an aperture of the objective [21]. The effect observed in Fig. 4 (left panel, bottom image), where several concentred zones of different density material can clearly be seen, seems to support this hypothesis. Alternatively, a strong temperature gradient at the edge of the site, resulting from the diffraction on the mask, could contribute to the radial mass transfer - an effect that deserves further investigation.

(a) $109 \mathrm{~mJ} / \mathrm{cm}^{2}, 400$ pulses

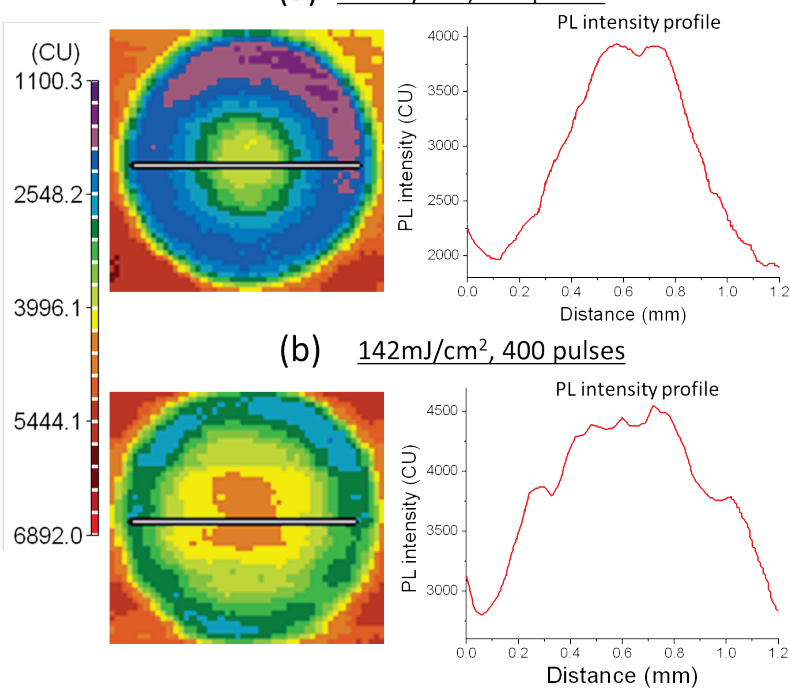

Fig. 7 PL peak intensity map and profile of the $\mathrm{KrF}$ laser irradiated spots with 400 pulses at $109 \mathrm{~mJ} / \mathrm{cm}^{2}$ (a) and 142 $\mathrm{mJ} / \mathrm{cm}^{2}(\mathrm{~b})$

Fig. 7 shows the PL peak intensity map of the $\mathrm{KrF}$ laser irradiated spots with 400 pulses at $109 \mathrm{~mJ} / \mathrm{cm}^{2}$ (a) and 142 $\mathrm{mJ} / \mathrm{cm}^{2}$ (b). The PL intensity has been expressed in calibrated units (CU) that refer to the intensity obtained after subtracting the background signal. The corresponding PL intensity profiles show that the PL intensity is significantly enhanced in the center of the irradiated sites, coinciding with the presence of the 130 and $180 \mathrm{~nm}$ tall nano-cone structures as seen in Fig. 6. The central region of the $109 \mathrm{~mJ} / \mathrm{cm}^{2}$ irradiated site (Fig. 7a) emits a PL signal about 2 times stronger than the edge region of that site. This difference is reduced to about 1.5 times for the 142 $\mathrm{mJ} / \mathrm{cm}^{2}$ irradiated site (Fig. $7 \mathrm{~b}$ ), although the maximum PL intensity in that case appears to be $10 \%$ greater than in Fig. 7a. The likely role of the nano-cone structures in enhancing the PL signal is related to the reduced reflection of the incident light (1064 nm) and, consequently, an enhanced laser pumping efficiency of the InP/InGaAs/InGaAsP microstructure. An increased light extraction efficiency has been reported for GaN-based light-emitting diodes (LEDs) with cone-shape surfaces [22]. The light output from InGaN/GaN LEDs with an $\mathrm{KrF}$ laser fabricated nano-cone surface structure has been reported to increase by 1.55 times in comparison to the conventionally fabricated LEDs [23]. Fig. 8 shows normalized PL intensities of the central region vs. the non-irradiated material for $\mathrm{KrF}$ laser operating at 109,124 and $142 \mathrm{~mJ} / \mathrm{cm}^{2}$. Initially, the PL intensity decreases, primarily due to the laser induced structural and chemical surface damage [24]. This coincides with no obvious nano-cone structures formation at sites irradiated with low pulse laser numbers $(\mathrm{N} \leq 100)$. However, the PL intensity increases for $\mathrm{N}>300$, i.e., for 
the samples with nano-cone microstructures as summarized in Fig. 6. The PL intensity variation with different laser fluences at the same pulse numbers is due to the different average height, size and period of the created selforganized nano-cone structures. With $124 \mathrm{~mJ} / \mathrm{cm}^{2}$ and 142 $\mathrm{mJ} / \mathrm{cm}^{2}$, when $\mathrm{N} \geq 400$, the PL intensity is greater than that in the non-irradiated material. The same results have been observed for the $109 \mathrm{~mJ} / \mathrm{cm}^{2}$ irradiated sites with $\mathrm{N} \geq 500$. This is obviously related to the nano-cones formation because the average height $(181 \mathrm{~nm})$, size $(670 \mathrm{~nm})$ and period $(870 \mathrm{~nm})$ of these structures at 500 pulses has increased to the values corresponding to the sites irradiated with 400 pulses at $142 \mathrm{~mJ} / \mathrm{cm}^{2}$ and $124 \mathrm{~mJ} / \mathrm{cm}^{2}$. The maximum normalized PL intensity enhancement factor of around 1.35 is observed for pulse number $\mathrm{N} \geq 600$. The inset in Fig. 8 shows PL spectra observed from the asgrown QW microstructure and central region of the sites irradiated with 400 pulses at 109 and $142 \mathrm{~mJ} / \mathrm{cm}^{2}$ and 700 pulses at $142 \mathrm{~mJ} / \mathrm{cm}^{2}$.

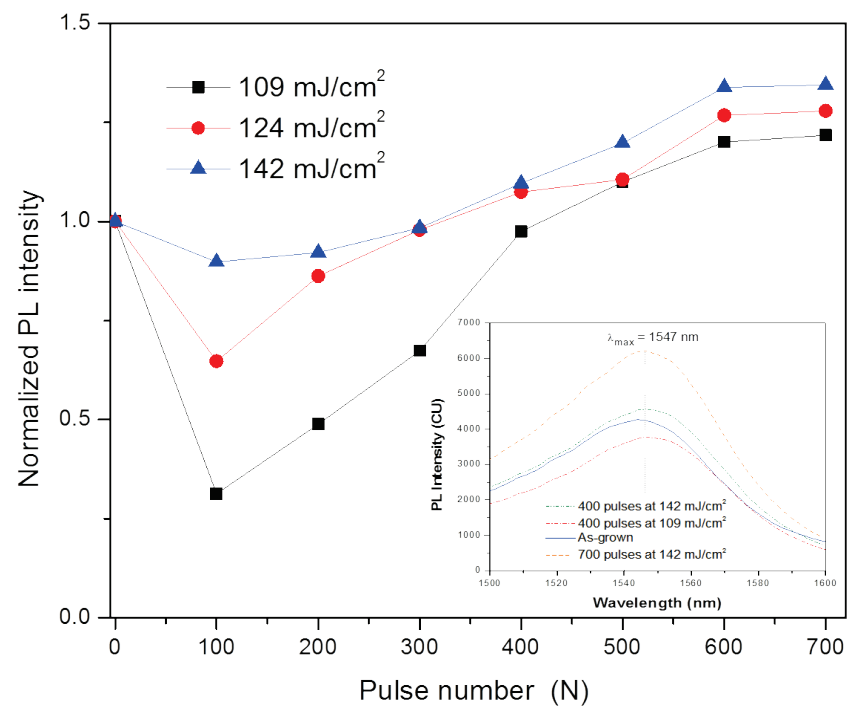

Fig. 8 Normalized PL intensity of the site central region vs. pulse number when irradiated with the $\mathrm{KrF}$ laser at $109 \mathrm{~mJ} / \mathrm{cm}^{2}$, $124 \mathrm{~mJ} / \mathrm{cm}^{2}$ and $142 \mathrm{~mJ} / \mathrm{cm}^{2}$. The inset shows PL spectra observed from the as-grown QW microstructure and the central region of the laser irradiated sites.

\subsection{ArF laser irradiation of InP/InGaAs/InGaAsP microstructures}

Similar surface morphology of the InP cap layer was observed following irradiation with the ArF laser. The 'darker' central and 'lighter' edge regions with different density and size of the nano-cone structures were observed by an optical microscope and AFM. Fig. 9 shows an AFM image and line profile of the central region of the ArF laser irradiated spots with 400 (a) and 700 (b) pulses at 95 $\mathrm{mJ} / \mathrm{cm}^{2}$. The average height, size and period of nano-cone structures are larger in the 700 pulses irradiates sites than with 400 pulses. Figure 10 summarizes the average height, size (diameter) and period of nano-cone structures (a) along with the normalized PL intensity (b) in the central region of ArF laser irradiated sites as a function of pulse number at $95 \mathrm{~mJ} / \mathrm{cm}^{2}$. It can be seen that the average size and period of nano-cone structures increase with the pulse number and saturate at 600 pulses, while the average height continues increasing up to 700 pulses. The average size and period of these nano-cones are smaller than those corresponding to the sites irradiated with the KrF laser. We did not identify any visible nano-cone structures at sites irradiated with the low number of pulses $(\mathrm{N} \leq 200)$ of the ArF laser. Related to this is the absence of an enhanced PL. As illustrated in Fig. 10 (b), the PL signal decays rapidly with pulse number,
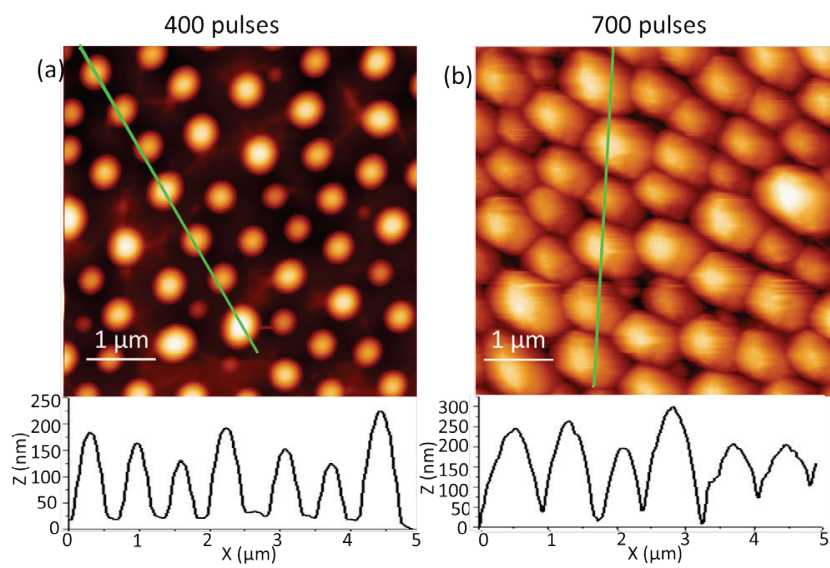

Fig. 9 AFM images and profiles along indicated lines of the central region of the ArF laser sites irradiated at $95 \mathrm{~mJ} / \mathrm{cm}^{2}$ with (a) 400 pulses and (b) 700 pulses.
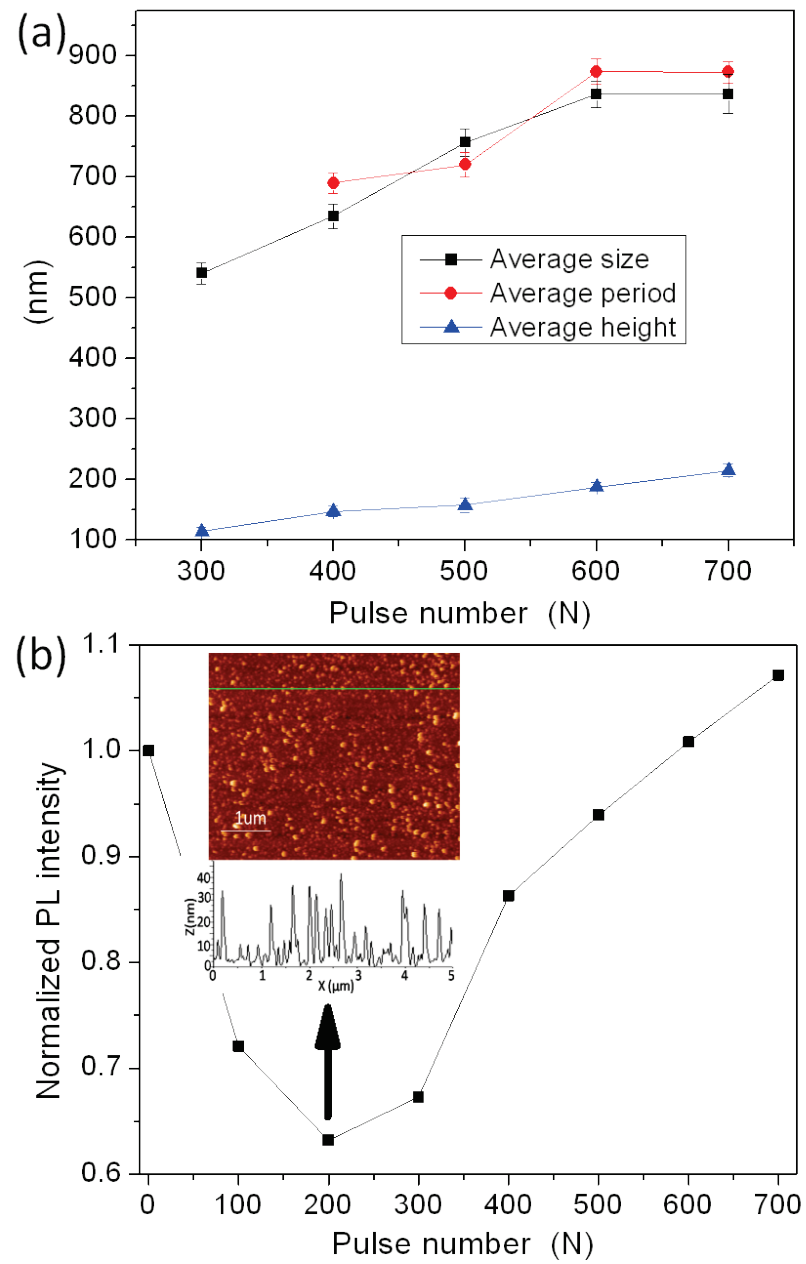

Fig. 10 Average size, period and height of the nano-cone structures (a) and normalized PL intensity (b) in the central region of the ArF laser irradiated sites at $95 \mathrm{~mJ} / \mathrm{cm}^{2}$. 
indicating that significant surface damage occurs in this case. An inset in Fig. 10 (b) shows an AFM image of the InP surface after it was irradiated with 200 pulses. Randomly distributed nanoparticles of maximum height nearing $40 \mathrm{~nm}$ can clearly be seen in the image. The $\sigma_{\mathrm{RMS}}$ roughness [12] of that sample was estimated at $7.5 \mathrm{~nm}$, which compares to $\sigma_{\mathrm{RMS}} \approx 0.9 \mathrm{~nm}$ for the surface of a nonprocessed sample. A qualitatively similar surface morphology and reduced PL intensity has also been observed for the site irradiated with 100 pulses of a $\mathrm{KrF}$ laser operating at $109 \mathrm{~mJ} / \mathrm{cm}^{2}$ (see Fig. 5a). An increasing PL intensity with increasing pulse number is observed in the $300 \leq \mathrm{N} \leq 700$ range. The PL intensity of the 600 -pulse irradiated site is about $25 \%$ greater than that on a nonirradiated site. This is related to the $\mathrm{ArF}$ laser-induced formation of nano-cone structures, as illustrated in Fig. 9. The average height, diameter and periodicity of the 600pulse created nano-cones are 188, 837 and $874 \mathrm{~nm}$, respectively. These results are comparable to those obtained with the $\mathrm{KrF}$ laser at 400 pulses and fluence of $142 \mathrm{~mJ} / \mathrm{cm}^{2}$. No formation of nano-cone structures was observed for the ArF laser operating at $82 \mathrm{~mJ} / \mathrm{cm}^{2}$, even up to 700 pulses.

\subsection{KrF and ArF laser irradiation of bulk InP wafer}

We have also irradiated bulk InP material with $\mathrm{KrF}$ and ArF laser using the same laser fluence and pulse number conditions as applied on InP/InGaAs/InGaAsP microstructures. Fig. 11 shows AFM images of a bulk InP sample irradiated with 400 and 700 pulses of the $\mathrm{KrF}$ laser at $142 \mathrm{~mJ} / \mathrm{cm}^{2}$. No obvious nano-cone structure is present in this case. Instead, a randomly formed pattern of nanoparticles is observed. These nanoparticles are approximately $160 \mathrm{~nm}$ wide and their average height is around 10 and $20 \mathrm{~nm}$ for the 400- and 700-pulse irradiated spots, respectively. Similar surface morphology was also observed during $\mathrm{KrF}$ laser assisted etching of bulk $\mathrm{InP}$ in $\mathrm{Cl}_{2}$ environment at $40 \mathrm{~mJ} / \mathrm{cm}^{2}$ with 600 pulses [20], although an even smoother surface of InP was reported in the $\mathrm{XeCl}$ excimer laser etching experiment of $\mathrm{InP}$ at 55 $\mathrm{mJ} / \mathrm{cm}^{2}$ with 2000 pulses in a $\mathrm{Cl}_{2} / \mathrm{H}_{2}$ environment [25]. No measurable changes to the surface morphology of bulk InP samples was observed following their irradiation with the $\mathrm{KrF}$ laser at $124 \mathrm{~mJ} / \mathrm{cm}^{2}$ and $109 \mathrm{~mJ} / \mathrm{cm}^{2}$. This suggests that the ablation threshold of bulk InP irradiated in air with $\sim 16 \mathrm{~ns}$ pulses at $248 \mathrm{~nm}$ is greater than $124 \mathrm{~mJ} / \mathrm{cm}^{2}$. For the ArF laser irradiated bulk InP, no evidence of material ablation was found for the pulse fluence of $95 \mathrm{~mJ} / \mathrm{cm}^{2}$ and up to 700 pulses. These differences in the observed ability of both $\mathrm{ArF}$ and $\mathrm{KrF}$ excimer lasers to modify the surface of the InP epi-layer interfaced with $\mathrm{InGaAs} / \mathrm{InGaAsP}$ QW microstructure and that of the bulk InP material are related to different optical properties of these materials, as well as to different temperature profiles and heat dissipation processes in bulk InP and epi-layer microstructures.

We note that the formation of the nano-cone structures observed in this experiment has been obtained with the ArF and $\mathrm{KrF}$ lasers operating above the fluence and pulse number used for the formation of the QWI material. Therefore, these nano-cone structures, while contributing to the enhanced PL emission from the InP/InGaAs/InGaAsP $\mathrm{QW}$ heterostructures, do not perturb the QWI process.
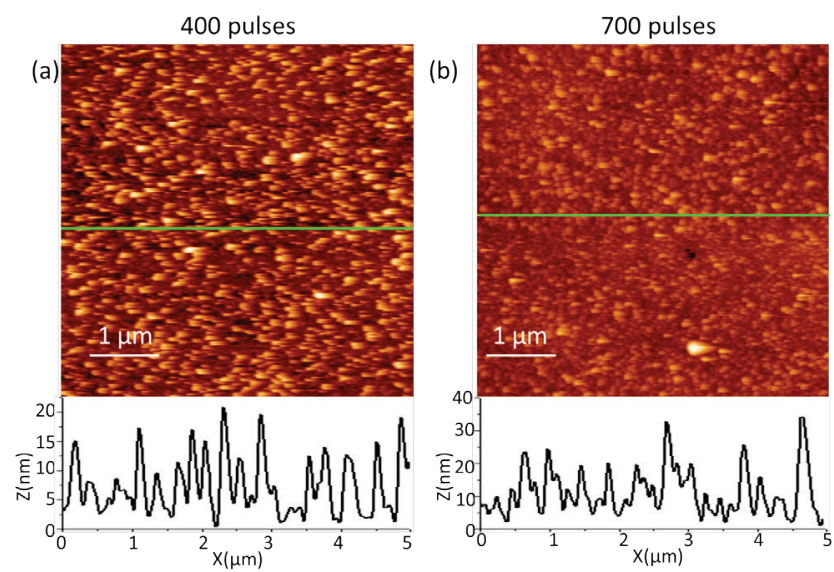

Fig. 11 AFM image of bulk InP irradiated with 400 (a) and 700 (b) pulses of the $\mathrm{KrF}$ laser operating at $142 \mathrm{~mJ} / \mathrm{cm}^{2}$.

\section{Conclusion}

Laser-induced formation of self-organized nano-cone arrays has been observed in InP/InGaAs/InGaAsP microstructures irradiated with $\mathrm{KrF}$ and $\mathrm{ArF}$ lasers at pulse fluence of $95-142 \mathrm{~mJ} / \mathrm{cm}^{2}$ and pulse number from 100 to 700. The average size, height and period of these nanocone structures increase with laser fluence and pulse number and saturates at larger pulse numbers $(\mathrm{N} \geq 600)$. No such surface structures have been observed in bulk InP irradiated with lasers under similar conditions. An enhanced QW PL emission has been observed from samples showing nano-cone structures, in proportion to their size and period. The maximum enhancement of $\sim 1.4 \mathrm{x}$ has been observed for samples irradiated with $\mathrm{KrF}$ laser. The formation of relatively weaker developed nano-cones in samples irradiated with the ArF laser is likely related to the weaker absorption of the $193 \mathrm{~nm}$ radiation in comparison to the $248 \mathrm{~nm}$ radiation by the investigated InP epi-film.

\section{Acknowledgments}

This work was supported by the Natural Science and Engineering Research Council of Canada and the Canada Research Chair in Quantum Semiconductors program (JJD). One of the authors (NL) wishes to acknowledge the support from the Merit Scholarship program for Foreign Students of the Fonds de Recherche sur la Nature et les Technologies du Québec. The help from the Centre de recherche en nanofabrication et en nanocaracterisation $\left(\mathrm{CNR}^{2}\right)$ and Centre de Caractérisation des Matériaux (CCM) of Université de Sherbrooke is greatly appreciated.

\section{References}

[1] D. Bauerle: "Laser Processing and Chemistry." ed. by S.-v. H. Berling (Springer Linz 2000) p.788.

[2] J. Dubowski, P. Poole, G. Sproule, G. Marshall, S. Moisa, C. Lacelle and M. Buchanan: Appl. Phys. A, 69, (1999) 299.

[3] J. Bonse, M. Munz and H. Sturm: IEEE Trans. Nanotechnol., 3, (2004) 358. 
[4] G. Miyaji and K. Miyazaki: J. Laser Micro/Nanoeng., 5, (2010) 86.

[5] B. N. Chichkov, C. Momma, S. Nolte, F. von Alvensleben and A. Tünnermann: Appl. Phys. A, 63, (1996) 109.

[6] O. R. Musaev, O. S. Kwon, J. M. Wrobel, D. M. Zhu and M. B. Kruger: Appl. Surf. Sci., 254, (2008) 5803.

[7] J. Genest, J. J. Dubowski and V. Aimez: Proc. of SPIE on Intergrated Optics and Photonics Circuits, Strasbourg, 8, (2004) 551.

[8] J. Genest, R. Beal, V. Aimez and J. Dubowski: Appl. Phys. Lett., 93, (2008) 071106.

[9] J. Genest, J. Dubowski, V. Aimez, N. Pauc, D. Drouin and M. Post: J. Phys. Conf. Ser., 59, (2007) 605.

[10] R. Hey, I. Gorbunova, M. Ramsteiner, M. Wassermeier, L. Daweritz and K. H. Ploog: J. Cryst. Growth, 175, (1997) 1167.

[11] C. Xu and T. Mei: IEEE J. Quantum Elect., 45, (2009) 920.

[12] N. Liu, K. Moumanis and J. J. Dubowski: Laser Applications in Microelectronic and Optoelectronic Manufacturing (LAMOM) XVI (2011) 79200C.

[13] D. Aspnes and A. Studna:Phys. Rev. B: Condens. Matter., 27, (1983) 985.

[14] A. Bulgakov, A. Evtushenko, Y. G. Shukhov, I. Ozerov and W. Marin: Quantum Electron., 40, (2010) 1021.

[15] O. Musaev, V. Dusevich, J. Wrobel and M. Kruger: J. Mater. Sci., 46, (2011) 1.
[16] G. Simpson, D. Sedin and K. Rowlen: Langmuir 15, (1999) 1429.

[17] V. Aimez, J. Beauvais, J. Beerens, D. Morris, H. S. Lim and O. Boon-Siew: IEEE J. Sel. Top Quant. 8, (2002) 870 .

[18] M. Fathipour, P. Boyer, G. Collins and C. Wilmsen: J. Appl. Phys., 57, (1985) 637.

[19] A. Medvid, A. Mychko, V. Gnatyuk, S. Levytskyi and Y. Naseka: Opt. Mater., 32, (2010) 836.

[20] O. Musaev, O. Kwon, J. Wrobel, D. M. Zhu and M. Kruger: Appl. Surf. Sci., 254, (2008) 5803.

[21] D. S. Shin, J. H. Lee, J. Suh and T. H. Kim: Opt. laser Eng. 44, (2006) 615.

[22] T. Fujii, A. David, Y. Gao, M. Iza, S. DenBaars, E. Hu, C. Weisbuch and S. Nakamura: Phys. Status Solidi C, 2, (2005) 2836.

[23] H. W. Huang, J. Chu, C. Kao, T. Hseuh, T. Lu, H. Kuo, S. Wang and C. Yu: Nanotechnology 16, (2005) 1844.

[24] M. Takai, J. Tsuchimoto, J. Tokuda, H. Nakai, K. Gamo and S. Namba: Appl. Phys. A, 45, (1988) 305.

[25] J. J. Dubowski, B. E. Rosenquist, D. J. Lockwood, H. J. Labbe, A. P. Roth, C. Lacelle, M. Davies, R. Barber, B. Mason and G. I. Sproule: J. Appl. Phys., 78, (1995) 548.

(Received: September 14, 2011, Accepted: February 15, 2012) 